\title{
Sensitivity of Seed Germination to Salt Stress in Teff [Eragrostis tef (Zucc.) Trotter]
}

\author{
Panayiota PAPASTYLIANOU ${ }^{1 *}$, Ilias TRAVLOS, Ioannis ROUSSIS, Dimitrios BILALIS \\ Agricultural University of Athens, School of Agriculture, Engineering and Environmental Sciences, \\ Department of Crop Science, Laboratory of Agronomy, 75 Iera Odos Str., 11855 Athens, Greece. \\ *corresponding author: ppapastyl@aua.gr
}

BulletinUASVM Horticulture 76(1) / 2019

Print ISSN 1843-5254, Electronic ISSN 1843-5394

DOI:10.15835/buasvmcn-hort: 2019.0004

\begin{abstract}
Teff is an annual grass originated in Ethiopia, grown for both human food and animal feed. Salinity and moisture stress are the main limiting factors of agricultural development on arid and semi-arid regions. The aim of this study was to investigate the effect of salinity due to $\mathrm{NaCl}$ on germination of teff. A set of experiments was conducted under a completely randomized design with four replications of 200 seeds at two different suboptimal germination temperatures $\left(15\right.$ and $\left.25^{\circ} \mathrm{C}\right)$ in the dark for 10 days. In order to create salt stress conditions during the germination process, seven solutions were used ( 0 as control, 80, 160, 240 and 320, 400 and $480 \mathrm{mM} \mathrm{NaCl}$ ). The germination performance was evaluated by final germination percentage and mean germination time. The presence of $\mathrm{NaCl}$ reduced germination, especially above $240 \mathrm{mM}$ for $15{ }^{\circ} \mathrm{C}$ and $400 \mathrm{mM}$ for $25^{\circ} \mathrm{C}$. The mean germination time increased with higher $\mathrm{NaCl}$ levels.
\end{abstract}

Keywords: germination percentage, germination time, $\mathrm{NaCl}$, salinity, teff

\section{Introduction}

Climate change is the greatest environmental threat facing humanity worldwide. Areas of SouthEast Europe and the Mediterranean basin are expected to beamong the mostvulnerable countries to climate change. Furthermore, in the semiarid regions of the Mediterranean region water and salinity stresses are increasingly becoming the primary limiting environmental conditions which restrict successful establishment of crops. As reported by Daliakopoulos et al. (2016), soil salinization in the Mediterranean region affects $25 \%$ of irrigated agricultural land at a significant level and about $9 \%$ of the 1.4 Mha of irrigated land in Greece is affected by soil salinization due to seawater intrusion. The establishment of new crops with better performance under stress conditions could be an alternative solution for modern farmers and an opportunity to cultivate innovative crops for alternative uses (Bilalis et al., 2017).
Teff [Eragrostis tef (Zucc.) Trotter] is an annual C4 grass crop that originated in Ethiopia and has been introduced to other countries such as India, Africa, Western Europe, Australia and the U.S.A. mainly as a forage crop (Bedane et al., 2015). It is grown for both human food and animal feed with an attractive nutritional profile, being high in dietary fibre, iron, calcium and carbohydrate, bearing also high levels of phosphorus, copper, aluminium, barium and thiamine (Hager et al., 2012). It has an excellent balance of amino acid composition (including all 8 essential amino acids for humans) making it an excellent material for malting and brewing (Gebremariam et al., 2014). It is also considered to be a healthy food since its grain is free of gluten, making it suitable for people suffering from celiac disease (Assefa et al., 2015). It grows in a wide range of environmental conditions and is more tolerant to drought, water logging and disease in comparison with other common cereals (Yihun et al., 2013). 


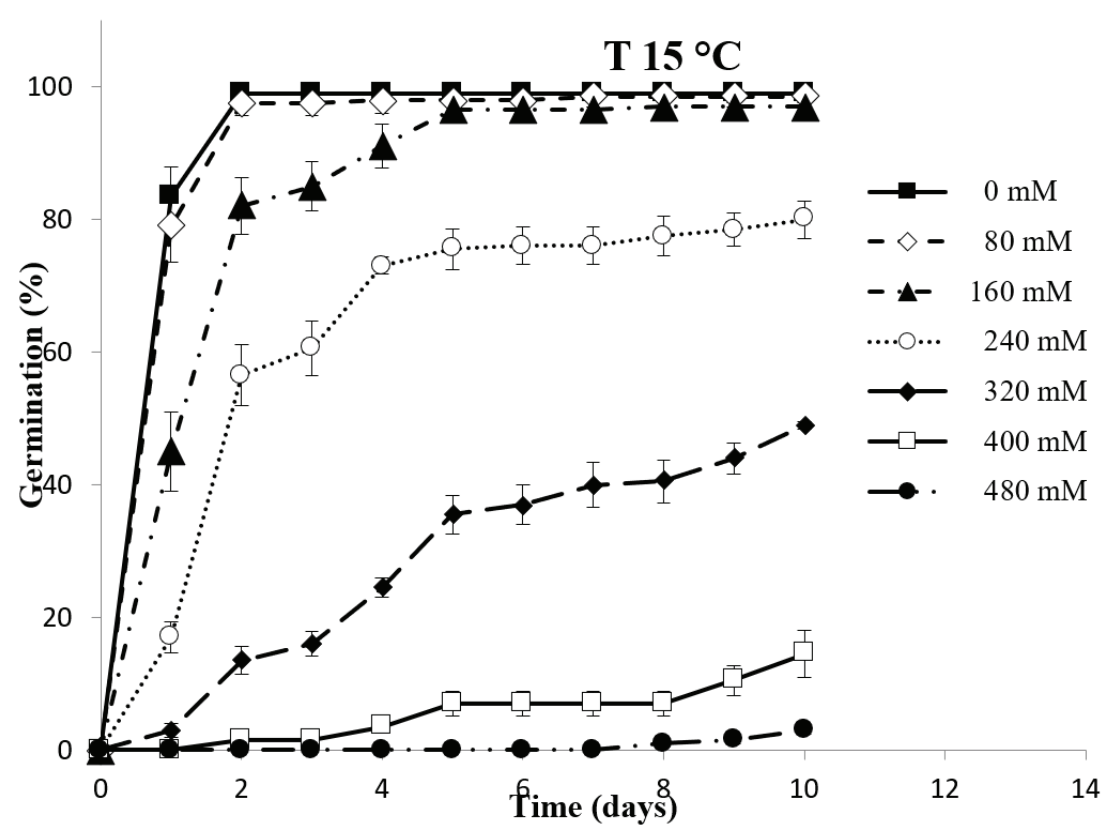

Figure 1. Cumulative germination of teff seeds exposed to $\mathrm{NaCl}$ solutions at $15^{\circ} \mathrm{C}$. Vertical bars represent the standard error.

Germination of high-quality seeds may be delayed or prevented by various abiotic stresses (Ashraf and Foolad, 2005). Seed germination and seedling growth may be significantly reduced and delayed by the decreasing rate of water absorption, when saline water is used for irrigation or when soil salinity is high. Under these conditions, salt stress may also cause excessive uptake of ions (Murillo-Amador et al., 2002). There is evidence that teff shows moderate tolerance to salinity stress (Kebebew and McNeilly, 1995). However, relative data are rather inadequate (Mamo et al., 1996; Abusuwar and Abbaker, 2009; Asfaw and Itanna, 2009).

The aim of the present study was to investigate the effect of salinity due to $\mathrm{NaCl}$ on germination of teff seeds.

\section{Materials and Methods}

Seeds of teff were surface sterilized in a $1 \%$ sodium hypochlorite solution, rinsed in distilled water and dried before the experiment ( $4.4 \%$ seed moisture). A set of experiments was conducted under a completely randomized design with four replications. Seeds were germinated at two constant temperatures $15{ }^{\circ} \mathrm{C}$ and $25{ }^{\circ} \mathrm{C}$ and maintained in a thermostatically controlled incubator $\left( \pm 1{ }^{\circ} \mathrm{C}\right)$ for 10 days. Samples of 800 seeds (four replicates of 200 seeds each) were placed in covered 9-cm Petri dishes between two
Whatman No. 1 filter papers moistened with 7 $\mathrm{mL}$ of $\mathrm{NaCl}$ solutions. Salt solutions were used in germination tests to imbibe seeds. Seven solutions were prepared, dissolving different concentrations of sodium chloride $(\mathrm{NaCl})$ in distilled water $(0$ as control, 80, 160, 240, 320, 400 and $480 \mathrm{mM}$ ). Petri dishes were hermetically sealed with parafilm to prevent evaporation and then randomized in an incubator in the dark. The seeds were kept in the dishes to assess germination. This was scored when the radicle approached approximately 2 $\mathrm{mm}$ length and data were collected daily until no additional germination had occurred for $48 \mathrm{~h}$.

At the end of the tests the final percentage of germination was calculated. Using the daily counts, the mean germination time (MGT) was calculated for each lot using the formula cited by Ellis and Roberts (1980) given below, MGT= $\sum$ n.D / $\sum \mathrm{n}$ where $\mathrm{n}=$ number of seeds newly germinated at time $\mathrm{D} ; \mathrm{D}=$ days from the beginning of the germination test, $\Sigma \mathrm{n}=$ final germination. Data of the final germination percentage (arcsine transformed) and mean germination time were statistically analyzed by a completely randomized two-way analysis of variance (ANOVA) using the StatSoft software (1999). The analysis of variance was conducted considering osmotic potential and temperatures as fixed factors. When ' $F$ ' ratios were significant, means were separated by the StudentNewman-Keuls (SNK) test at $\leq 0.05$. 


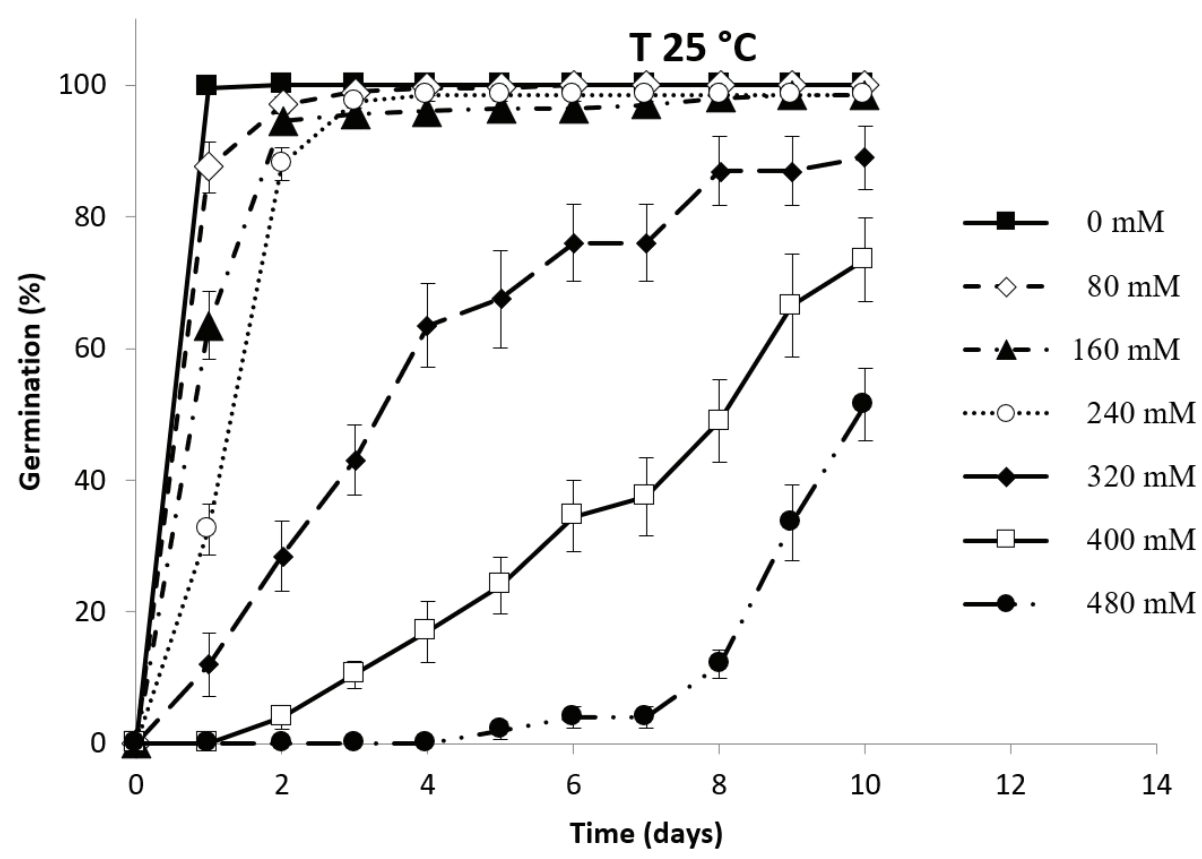

Figure 2. Cumulative germination of teff seeds exposed to $\mathrm{NaCl}$ solutions at $25^{\circ} \mathrm{C}$. Vertical bars represent the standard error.

\section{Results and Discussion}

The cumulative seed germination time courses during imbibition at different concentrations in $\mathrm{NaCl}$ solution are shown in Figures 1 and 2 . Final germination percentage of the controls was $99 \%$ and $100 \%$ at $15{ }^{\circ} \mathrm{C}$ and $25{ }^{\circ} \mathrm{C}$, respectively. Comparable results were reported by Vecchio et al. (1996) who found that germination percentage of teff seeds starting from $15^{\circ} \mathrm{C}$ was above $90 \%$. Several authors have reported that salinity stress affects seed germination either by decreasing the rate of water uptake (osmotic effect) and/ or by facilitating the intake of ions (ion toxicity), which may change enzymatic or hormonal activities inside the seed (Murillo-Amador et al., 2002; Ashraf and Foolad, 2005). In general, seeds from the controls showed a higher rate of final germination percentage and a lower mean germination time compared to seeds from the salt treatments. The effect of salinity on seed germination percentage and mean germination time was significant at $\mathrm{p}<0.001$ (Tab. 1). The presence of $\mathrm{NaCl}$ regardless of temperature reduced germination. This reduction was more severe at $15{ }^{\circ} \mathrm{C}(49 \%, 15 \%$ and $3 \%$ germination in case of 320,400 , and $480 \mathrm{mM}$ concentration respectively) than at $25{ }^{\circ} \mathrm{C}(74 \%$ and $52 \%$ at 400 $\mathrm{mM}$ and $480 \mathrm{mM}$ salinity level) (Figs. 1 and 2, Tab. 1). Mean germination time ranged from 1 to 2 days at lower salt concentration. Excessive salinity caused a significant delay in mean germination time $(7$ and 9 days at $400 \mathrm{mM}$ and $480 \mathrm{mM}$ concentration, respectively) regardless of temperature (Tab. 1). Similar effects were observed in seed germination, seedling emergence and seedling growth of teff in the laboratory and the field (Kebebew and McNeilly 1995; Mamo et al., 1996).

Moreover, our results were in agreement with the findings of Abusuwar and Abbaker (2009), Asfaw and Itanna (2009) and Mamo et al. (1996) who found that high levels of salinity can significantly inhibit seed germination in teff. In particular, increasing of salinity from 4 to $8 \mathrm{dS}$ $\mathrm{m}^{-1}$ reduced the seed germination percentage and delayed germination time of various teff genotypes and no germination occurred in the highest salinity stress of $16 \mathrm{dS} \mathrm{m}^{-1}$. Saline soil causes physiological and metabolic disorders in seed germination, morphological characteristics of plants, affecting development, growth, yield, and quality of plants (Gorham, 1990; Asfaw and Itanna 2011). Salinity sensitivity of teff varied in different growth stages, from germination to harvest (Mamo et al., 1996). According to this experiment, varieties that showed the highest mean germination percentage and relative seedling shoot dry weight also had the highest mean relative shoot dry weight at the late vegetative stage and others that had a slow 
Table 1. Results from an analysis of variance showing the effects of $\mathrm{NaCl}$ solutions on final germination percentage and mean germination time of teff seeds germinated at $15^{\circ} \mathrm{C}$ and $25^{\circ} \mathrm{C}$.

\begin{tabular}{|c|c|c|c|c|}
\hline & \multicolumn{2}{|c|}{ Germination (\%) } & \multicolumn{2}{|c|}{ Mean germination time (days) } \\
\hline $\mathrm{C}(\mathrm{mM})$ & $15^{\circ} \mathrm{C}$ & $25^{\circ} \mathrm{C}$ & $15^{\circ} \mathrm{C}$ & $25^{\circ} \mathrm{C}$ \\
\hline 0 & $99.0 \mathrm{a}$ & $100 \mathrm{a}$ & $1.16 \mathrm{a}$ & $1.00 \mathrm{a}$ \\
\hline 80 & $98.5 \mathrm{a}$ & $100 \mathrm{a}$ & $1.23 \mathrm{a}$ & $1.18 \mathrm{a}$ \\
\hline 160 & $97.0 \mathrm{ab}$ & $98.5 \mathrm{a}$ & $1.89 \mathrm{a}$ & $1.52 \mathrm{a}$ \\
\hline 240 & $80.0 \mathrm{~b}$ & $98.5 \mathrm{a}$ & $2.62 \mathrm{~b}$ & $1.79 \mathrm{a}$ \\
\hline 320 & $49.0 \mathrm{c}$ & $89.0 \mathrm{a}$ & $4.83 \mathrm{c}$ & $3.98 \mathrm{~b}$ \\
\hline 400 & $14.5 \mathrm{~d}$ & $73.5 \mathrm{~b}$ & $6.81 \mathrm{~d}$ & $6.70 \mathrm{c}$ \\
\hline 480 & $3.0 \mathrm{e}$ & $51.5 \mathrm{c}$ & $8.88 \mathrm{e}$ & $8.94 \mathrm{~d}$ \\
\hline Average & $63 \mathrm{~A}$ & $87.3 \mathrm{~B}$ & $3.92 \mathrm{~A}$ & $3.59 \mathrm{~B}$ \\
\hline \multicolumn{5}{|l|}{ Significance } \\
\hline $\mathrm{C}$ & \multicolumn{2}{|c|}{$* * *$} & \multicolumn{2}{|c|}{$* * *$} \\
\hline $\mathrm{T}$ & \multicolumn{2}{|c|}{$* * *$} & \multicolumn{2}{|c|}{$* *$} \\
\hline $\mathrm{C} \times \mathrm{T}$ & \multicolumn{2}{|c|}{$* * *$} & \multicolumn{2}{|c|}{ ns } \\
\hline
\end{tabular}

C, salt concentrations, T, temperatures. ns, not significant; significant at ${ }^{*} p<0.05,{ }^{* *} p<0.01,{ }^{* * *} p<0.001$. Percentage data were transformed before analysis; actual values (means of the main factors) are shown. Values belonging to the same characteristic with different lower-case letters within a column indicate significant differences between osmotic potential mean values and different upper-case letters within a row indicate significant differences between the means of temperatures tested according to Student-Newman-Keuls test at $\mathrm{p}<0.05$.

start at germination and seedling stages exhibited the highest mean relative root dry weight at a later stage. These results confirm that whether the degree of emergence and seedling vigour was positively correlated with relative dry matter yield at maturity depended on the varieties. This observation supported the general belief that salt tolerance is not a constant trait over the plant's life cycle but varies with the environment and growth stage of the plant.

The overall results of this experiment showed the non-inhibitory effects of salt stress on seed germination parameters of teff in lower salt concentration. The lowering of the temperature makes the seeds more sensitive to salinity and at $15{ }^{\circ} \mathrm{C}$ seed germination below $320 \mathrm{mM}$ declines rapidly.

\section{References}

1. Abusuwar AO, Abbaker JA (2009). Effect of Different Concentrations of Red Sea Water on Germination and Growth of Some Forage Species. Sudan Journal of Desertification Research, 1(1): 109-125.

2. Asfaw KG, Itanna F (2009). Screening Some Tef [Eragrostis Tef (Zucc.)Trotter] Accessions/Varieties for Salt Tolerance during Germination and Seedling Stage. Mekelle University (MEJS) 1(2): 17-29.

3. Asfaw KG, Itanna F (2011). Response of dry matter production of tef (Eragrostis tef Zucc. Trotter) accessions and varieties to $\mathrm{NaCl}$ salinity. Current Research Journal of Biological Sciences, 3(4): 300-307.
4. Ashraf M, Foolad MR (2005). Pre-sowing seed treatment-a shotgun approach to improve germination, plant growth, and crop yield under saline and non-saline conditions. Advances in Agronomy, 88: 223-271.

5. Assefa K, Cannarozzi G, Girma D, Kamies R, Chanyalew S, Plaza-Wüthrich S, Blösch R, Rindisbacher A, Rafudeen S, Tadele Z (2015). Genetic diversity in tef [Eragrostis tef (Zucc.) Trotter]. Frontiers in Plant Science, 6: 177.

6. Bedane GM, Saukuru AM, George DL, Gupta ML (2015). Evaluation of teff [Eragrostis tef (Zucc.] Trotter) lines for agronomic traits in Australia. Australian Journal of Crop Science, 9(3): 242-247.

7. Bilalis D, Roussis I, Fuentes F, Kakabouki I, Travlos I (2017). Organic Agriculture and Innovative Crops under Mediterranean Conditions. Notulae Botanicae Horti Agrobotanici Cluj-Napoca, 45(2): 323-331.

8. Daliakopoulos IN, Tsanis IK, Koutroulis A, Kourgialas NN, Varouchakis AE, Karatzas GP, Ritsema CJ (2016). The threat of soil salinity: A European scale review. Science of the Total Environment, 573: 727-739.

9. Ellis RH, Roberts EH (1980). Towards a rational basis for testing seed quality. In P.D. Hebblethwaite (Ed.), Seed Production (pp. 605-635). Butterworths, London.

10. Gebremariam MM, Zarnkow M, Becker T (2014). Teff (Eragrostis tef) as a raw material for malting, brewing and manufacturing of gluten-free foods and beverages: a review. Journal of Food Science and Technology, 51(11): 2881-2895.

11. Gorham J, Hardy CA (1990). Response of Eragrostis tef to salinity and acute water shortage. Journal of Plant Physiology, 135: 641-645.

12. Hager AS, Wolter A, Jacob F, Zannini E, Arendt EK (2012). Nutritional properties and ultra-structure of commercial gluten free flours from different botanical sources 
compared to wheat flours. Journal of Cereal Science, 56: 239-247.

13. Kebebew F, McNeilly T (1995). Variation in response of accessions of minor millets, Pennisetum americanum (pearl millet) and Eleusine coracana (finger millet), and Eragrostis tef (tef) to salinity in early seedling growth. Plant and Soil, 175: 311-321.

14. Mamo T, Richter C, Heiligatag B (1996). Response of some varieties of durum wheat and tef to salt stress. African Crop Science Journal, 4(4): 423-432.

15. Murillo-Amador B, Lopez-Aguilar R, Kaya C, LarrinagaMayoral J, Flores-Hernandez A (2002). Comparative effects of $\mathrm{NaCl}$ and polyethylene glycol on germination, emergence and seedling growth of cowpea. Journal of Agronomy and Crop Science, 188: 235-247.

16. Vecchio V, Simoni G, Casini P (1996). Optimum germination temperature and cold tolerance of teff. Rivista di Agronomia, 30: 629-636.

17. Yihun YM, Haile AM, Schultz B, Erkossa T (2013). Crop Water Productivity of Irrigated Teff in a Water Stressed Region. Water Resources Management, 27: 3115-3125. 